\title{
Composição química e cinética de degradação ruminal da aveia branca (Avena sativa $L$.) cv. IPR126 sob diferentes níveis de nitrogênio
}

\section{Chemical composition and ruminal degradability of white oat ("Avena sativa” L.) cv. IPR126 under different nitrogen levels}

\author{
PERETTI, Jaidson ${ }^{*}$; HENRIQUE, Douglas Sampaio ${ }^{2}$; MAYER, Lilian Regina Rothe ${ }^{2}$; \\ MILITÃO, Erica Rui ${ }^{3}$; SCHIMITZ, Rafael ${ }^{3}$; BOGER, Deividy Tiago ${ }^{3}$; RÖSLER, \\ Jucemara Aparecida ${ }^{3}$
}

\footnotetext{
${ }^{1}$ Universidade Tecnológica Federal do Paraná, Programa de Pós Graduação em Zootecnia, Dois Vizinhos, Paraná, Brasil.

${ }^{2}$ Universidade Tecnológica Federal do Paraná, Departamento de Zootecnia, Dois Vizinhos, Paraná, Brasil.

${ }^{3}$ Universidade Tecnológica Federal do Paraná, Curso de Zootecnia, Dois Vizinhos, Paraná, Brasil.

*Endereço para correspondência: jaidson_peretti@yahoo.com.br
}

\section{RESUMO}

O trabalho visa à reunião de dados sobre composição bromatológica e perfil de degradação da IPR 126, adubada com níveis de $0,180,360$ e $720 \mathrm{~kg} \mathrm{ha}^{-1}$ de $\mathrm{N}$, na forma de ureia, sendo aplicadas na implantação e após cada corte, com intervalo de 21 dias entre cortes. Analisou-se a Matéria Seca (MS), Matéria Mineral (MM), Extrato Etéreo (EE), Proteína Bruta (PB), Fibra em Detergente Neutro e Ácido (FDN e FDA), Lignina (LIG), Proteína Insolúvel em Detergente Neutro e Ácido (PIDN e PIDA) e Carboidratos Totais e Solúveis (CT e CHOs), e estimaram-se os parâmetros de cinética de degradação: volume máximo e taxa específica de produção de gás pela degradação da fração solúvel de rápida digestão $\left(V f_{l}\right.$ e $\left.k_{l}\right)$; volume máximo e taxa específica de produção de gás pela degradação da fração insolúvel potencialmente degradável de digestão lenta $\left(V f_{2}\right.$ e $\left.k_{2}\right)$ e latência $(\lambda)$, pertencentes ao modelo logístico bicompartimental. O delineamento experimental foi blocos ao acaso, e a estrutura da matriz $\mathrm{R}$ adequada para cada parâmetro foi escolhida a partir da diferença entre os valores de Critério de Informação de Akaike Corrigido (AICc) representado pelo delta $\mathrm{r}\left(\Delta_{\mathrm{r}}\right)$. O nível de adubação causou aumento linear no teor de PB, e diminuição linear no teor de CT. O parâmetro $\lambda$ variou de forma quadrática em função do nível de adubação. Os demais nutrientes e parâmetros não apresentaram variância significativa em função dos tratamentos. Não foi alcançada a fase assintótica da concentração de proteína, mesmo utilizando altas doses de nitrogênio.

Palavras-chaves: adubação, bromatologia, cinética de produção de gases, forragicultura

\section{SUMMARY}

The present work aims to generate data on chemical composition and degradation profile of IPR 126, fertilized at levels of $0,180,360$ and $720 \mathrm{~kg} \mathrm{ha}^{-1}$ of $\mathrm{N}$ as urea, being applied in the implementation and after each cut with an interval of 21 days between cuts. The Dry Matter (DM), ash, Ether Extract (EE), Crude Protein (CP), Neutral and Acid Detergent Fiber (NDF and ADF), Lignin (LIG), Neutral and Acid Detergent Insoluble Protein (NDIP and ADIP) and Total and Soluble Carbohydrates (TC and CHOs) were determined, and we estimate the degradation kinetics parameters: maximum volume and specific rate of gas production by the degradation of soluble fractions of rapid digestion $\left(\left(V f_{l}\right.\right.$ and $\left.k_{l}\right)$; maximum volume and specific rate of gas production by the degradation of potentially degradable insoluble fraction of slow digestion $\left(V f_{2}\right.$ and $k_{2}$ ) and latency $(\lambda)$, belonging to the two-compartment logistic model. The experimental design was a randomized block 
design and structure of $\mathrm{R}$ suitable matrix for each parameter was chosen from the difference between the CorrectedAkaike Information Criterion values (AICc) represented by delta $r(\Delta r)$. The fertilization level caused a linear increase in CP content, and linear decrease in TC content. The parameter $\lambda$ varied quadratically with the level of fertilization. The other nutrients and parameters showed no significant variance in the treatments. The asymptotic phase of protein concentration was not reached, even using high doses of nitrogen.

Keywords: fertilization, food science, forage crops, gas production kinetics

\section{INTRODUÇÃO}

No sul do Brasil, a estação fria bem definida, caracterizada pela redução do foto-período, temperaturas baixas $\mathrm{e}$ ocorrência de geadas, favorece a utilização estratégica de espécies forrageiras anuais, adaptadas a estas condições, na alimentação do gado quando as forrageiras tropicais são escassas (NIMER, 1977; SOUZA et al., 2009). As gramíneas de clima temperado mais utilizadas são a aveia preta (Avena strigosaSchreb.), a aveia branca (Avena sativa L.), o azevém (Loliummultiflorum) e o trigo (TriticumaestivunL.) (ROSO et al., 1999; CARVALHO et al., 2010; MOREIRA et al., 2005).

Nos últimos anos, com o aumento dos sistemas de integração lavoura-pecuária, a aveia branca IPR 126, melhorada em 2005 pelo Instituto Agronômico do Paraná (IAPAR, 2007) tem sido muito utilizada, pois é um genótipo de ciclo longo, que proporciona oferta de volumoso por mais tempo durante o inverno, e indicada para produção de forragem, rotação de culturas $\mathrm{e}$ cobertura de solo para plantio direto (GOMES \& REIS, 1999; CARVALHO et al., 2010; ADAMI \& PITTA, 2012).

$\mathrm{A}$ aplicação de $\mathrm{N}$ é fundamental para o desenvolvimento das plantas e pode melhorar a qualidade nutricional das forrageiras, pois influencia o teor de proteína bruta (MOREIRA \& SIQUEIRA, 2006) e, em alguns casos, diminui o teor de fibra (BURTON \& MONSON, 1988). Segundo Olson \& Kurtz (1982), Santi et al. (2000) e Lima et al. (2001) o nitrogênio estimula o crescimento das raízes e a síntese de clorofila, aumentando a absorção de outros nutrientes e a quantidade de carboidratos produzida pela aveia. Por outro lado, níveis muito altos de $\mathrm{N}$ causam o aumento na pressão osmótica do solo devido ao excesso de sais solúveis, o que pode desidratar a planta, mesmo em solos úmidos (EMBRAPA, 2006; Al-KARAKAI et al., 2009; SCHOSSLER et al., 2012).

O objetivo do presente trabalho foi avaliar a composição química e a cinética de produção de gases da aveia branca (Avena sativa L.) IPR 126 submetida a doses crescentes de adubação nitrogenada e cortada em intervalo de tempo fixo.

\section{MATERIAIS E MÉTODOS}

O trabalho de campo foi realizado na região sudoeste do estado do Paraná, Brasil, com altitude de $520 \mathrm{~m}$, latitude de $25^{\circ} 44$ Sul e longitude de $54^{\circ} 04$ Oeste (MAACK, 1968). O clima é do tipo subtropical úmido mesotérmico (Cfa), segundo a classificação de Köppen (ALVARES et al., 2013), e com o solo classificado como Latossolo Vermelho Distroférrico de textura argilosa (EMBRAPA, 2006). Foi realizado no período de Abril a Setembro de 2013, sendo a área experimental constituída por três blocos com quatro parcelas de seis $\mathrm{m}^{2}(2 \times 3$ $\mathrm{m})$, com espaçamento entre blocos de $0,5 \mathrm{~m}$, sendo cada bloco uma repetição, 
a fim de amenizar os efeitos da declividade do terreno, que, por mais suave que fosse, poderia apresentar alguma interferência nos resultados a serem obtidos.

O preparo do solo foi sob resteva de mucuna (Mucunaaterrinavc. Mucuna preta), realizando aplicação de adubação de base de $145 \mathrm{~kg} \mathrm{ha}^{-1}$ da formulação pronta 08-20-10 (N-P-K) com uma semeadora de plantio direto $(22 \mathrm{~cm}$ entre-linhas), e adubação de cobertura com $\mathrm{N}$ nos fracionamentos de 0,180 , 360 e $720 \mathrm{~kg} \mathrm{ha}^{-1}$ de $\mathrm{N}$, usando ureia fracionada em três aplicações: a primeira logo após o corte de padronização e as subsequentes com 21 e 42 dias após o primeiro corte.
Efetuou-se um corte de padronização no momento que as plantas atingiram, aproximadamente, $25 \mathrm{~cm}$ de altura e os cortes subsequentes foram realizados a cada 21 dias, pelo método de estimativa visual direta com dupla amostragem (WILM et al, 1944; MANNETJE, 2000), sendo delimitada uma área de um metro quadrado $\left(\mathrm{m}^{2}\right)$ para a coleta do material, mantendo distância da bordadura da parcela e uma altura residual para rebrota de $10 \mathrm{~cm}$ acima do solo. Foram realizadas duas simulações pluviométricas de 10 milímetros posteriormente à aplicação do $\mathrm{N}$ devido à escassez de chuvas no período, confome pode ser observado nos dados meteorológicos do período do experimento (Figuras 1 e 2).

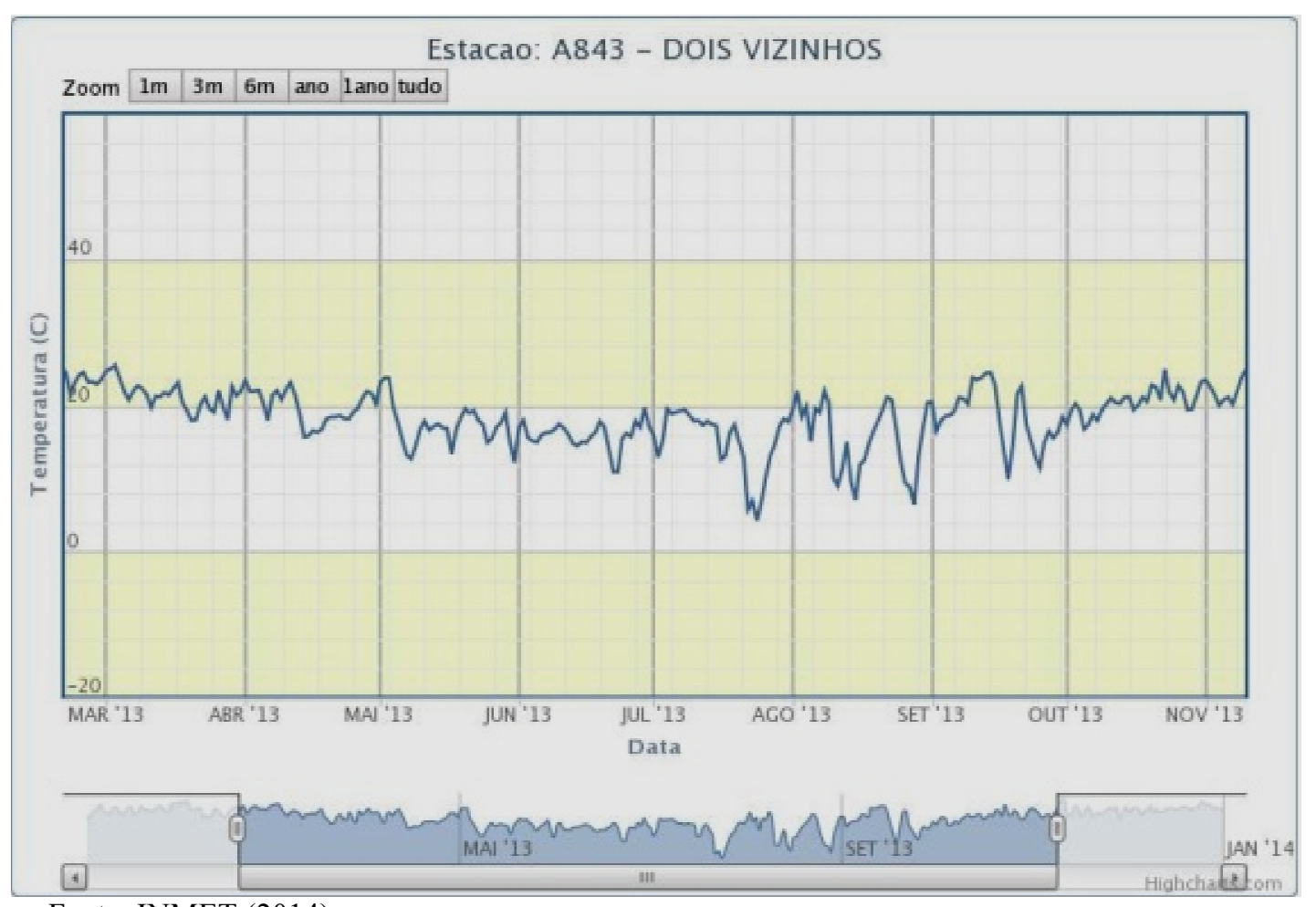

Fonte: INMET (2014)

Figura 1. Dados de temperatura $\left({ }^{\circ} \mathrm{C}\right)$ da Estação Meteorológica do campus Dois Vizinhos entre os meses de abril a setembro de 2013 


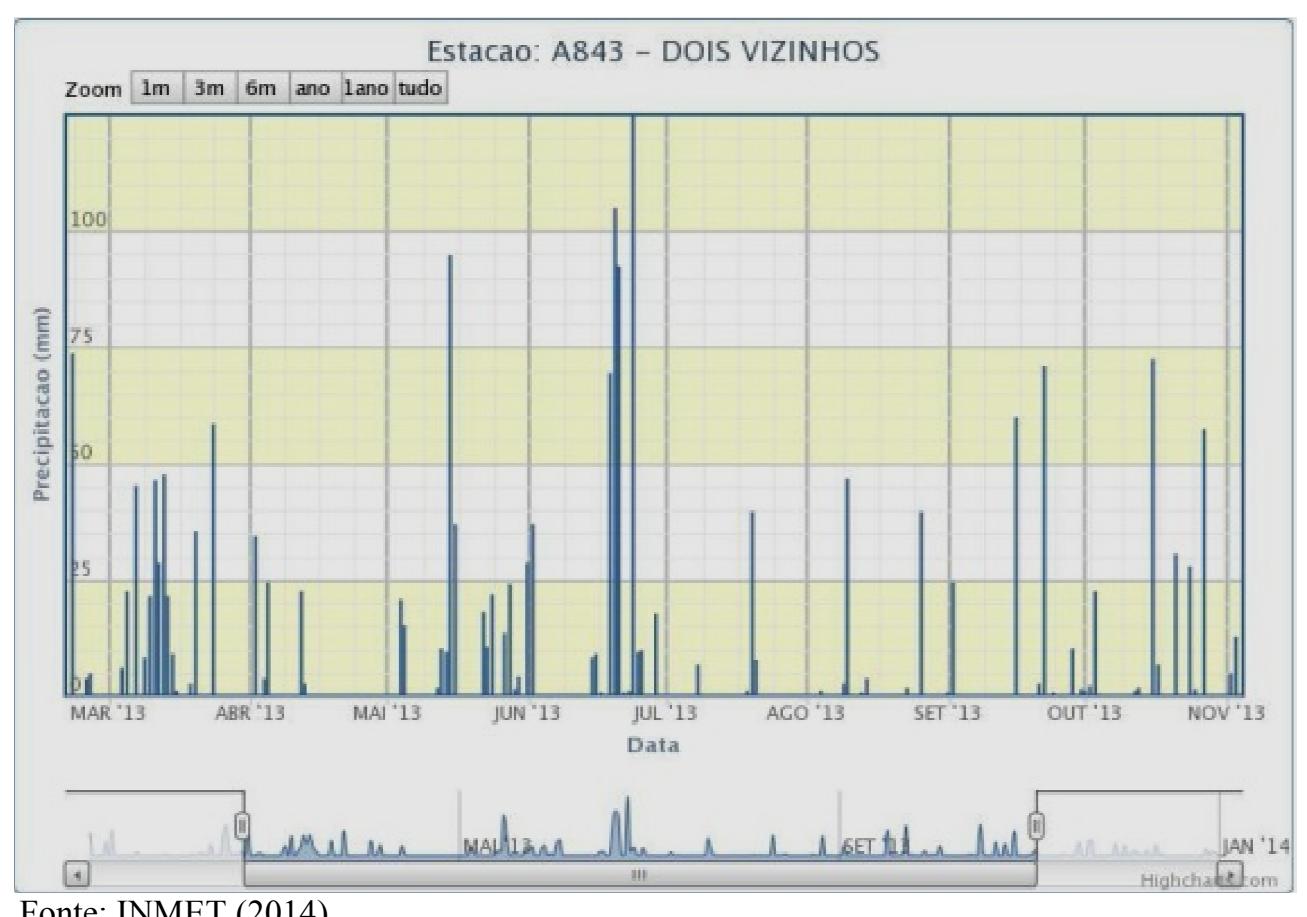

Fonte: INMET (2014)

Figura 2. Dados de precipitação da Estação Meteorológica do campus Dois Vizinhos entre os meses de abril a setembro de 2013

A espécie avaliada foi a Avena sativa L., variedade IPR126, da qual se comparou as variáveis por bloco e por níveis de adubação, mostrando a qualidade nutricional da forrageira. As amostras coletadas foram encaminhadas para a sala de estufas para determinação da matéria parcialmente seca (MPS). As análises bromatológicas foram realizadas no laboratório de Análise de Alimentos da UTFPR - Câmpus Dois Vizinhos, sendo determinados: a matéria seca (MS), matéria mineral (MM), extrato etéreo (EE) e proteína bruta $(\mathrm{PB})$, de acordo com a metodologia descrita por Silva \& Queiroz (2002); A análise de fibra insolúvel em detergente neutro (FDN) foi realizada segundo recomenda Mertens et al. (2002); a fibra insolúvel em detergente ácido (FDA), lignina (LIG), proteína insolúvel em detergente neutro (PIDN), proteína insolúvel em detergente ácido (PIDA) e carboidratos solúveis (CHOs) foram analisados de acordo com Van Soest \& Robertson
(1985); e os carboidratos totais (CT) foram estimados conforme modelo proposto por Sniffen et al. (1992).

A digestibilidade in vitro foi determinada seguindo todas as recomendações de Goering \& Van Soest (1975) e Abreu et al. (2014).

As leituras de pressão e de volume foram realizadas a $1,2,3,6,8,10,12,16,20$, $24,30,36,48,72$, e $96 \mathrm{~h}$ após a incubação. As leituras de volume foram expressas em mL/0,1 g de MS. Ao final do período total de incubação foi aferido o valor do $\mathrm{pH}$ do substrato incubado em cada frasco, com a utilização de phmetro devidamente calibrado. As curvas de produção acumulativa de gases observados in vitro foram ajustadas ao modelo logístico bicompartimental (SCHOFIELD et al., 1994). Os parâmetros ajustados no modelo logístico bicompartimental foram estimados pelo procedimento NLIN do aplicativo SAS ${ }^{\circledR}$ (versão 9.0) com o método de Marquardt. 
O delineamento experimental utilizado foi blocos ao acaso, com quatro doses de nitrogênio distribuídas em três blocos.

Para averiguar se houve efeito de tratamento foi realizada a análise de medidas repetidas no tempo usando o PROC MIXED do programa SAS $^{\circledR}$ (v.9.0) e a máxima verossimilhança restrita (REML) como o método de estimativa considerando o efeito fixo dos níveis de adubação e os efeitos aleatórios dos blocos e dos cortes (tempo) e o erro aleatório. Para a modelagem da matriz de variância e covariância (matriz R), foram testadas quatro estruturas: VC (componentes de variância), CS (simetria composta), AR (1) (auto regressiva de primeira ordem) e UN (matriz irrestrita) (LITTEL et al., 1996; LITTEL et al., 1998). A estrutura da matriz $\mathrm{R}$ adequada para cada parâmetro foi escolhida a partir da diferença entre os valores de Critério de Informação de Akaike Corrigido (AICc) representado pelo $\Delta_{\mathbf{r}}$. Para cada matriz foi calculado um $\Delta_{\mathbf{r}}$, por meio da diferença entre o valor de AICc, da matriz em questão, e o menor valor de AICC dentre todas as matrizes (BURNHAM \& ANDERSON, 2004; VIEIRA et al., 2012).

Valores de $\Delta_{r}$ entre 0 e 2, indicam que os modelos são equivalentes em minimizar a perda de informação e podem ser considerados equivalentes em sua qualidade de ajuste, sendo preferível escolher o modelo mais simples (BURNHAM \& ANDERSON, 2004, VIEIRA et al., 2012).

Após definida a melhor estrutura da matriz $\mathrm{R}$, o resultado do teste de efeito fixo (doses de $\mathrm{N}$ ) obtido com esta matriz era usado como critério decisório acerca da significância do efeito de tratamento $(\alpha=0,05)$. Nos casos em que o efeito de tratamento (doses de N) foi considerado significativo, as variáveis obtidas nas análises bromatológicas e os parâmetros estimados para o modelo bicompartimental de Schofield foram submetidos à análise de regressão das estimativas dos parâmetros em função dos tratamentos. Foram testados os modelos de regressão linear, quadrático e cúbico. Sendo o modelo escolhido de acordo com a significância dos parâmetros, avaliada por meio do valor $\mathrm{p}$. Se o valor $\mathrm{p}$ do parâmetro fosse $\leq 0,05$ o parâmetro era considerado significativo. O nível de confiança adotado em todas as análises foi de 0,95. Os dados bromatológicos, por se tratarem de proporções, foram transformados com o método do arco seno antes de se proceder à análise, para que essa transformação normalize a distribuição dos dados (CUSTÓDIO \& BARBIN, 2005).

Todas as variáveis possuíam medidas repetidas no tempo, devido aos diferentes cortes que foram feitos nas mesmas unidades experimentais.

A estimativa do intervalo de confiança (IC 95\%) para as médias das variáveis dependentes $(\sqrt{\bar{y}})$ foi determinada da seguinte maneira: $\bar{y}= \pm(L s-L i) / 2$, em que Ls e Li são respectivamente o limite superior e inferior do IC 95\% estimados pelo SAS $^{\circledR}$ (versão 9.0) (LITTELL, 2006).

\section{RESULTADOS E DISCUSSÃO}

A estrutura de matriz de variância e covariância que apresentou o melhor ajuste para a PB, EE, MM, FDN, PIDA e CT foi a VC (Tabelas 1 e 2). Para as variáveis CHOs, LIG, PIDN e MS, houve mais que uma matriz com ajuste adequado, sendo escolhida entre elas a VC pela sua maior simplicidade (Tabelas 1 e 2) (BURNHAM \& ANDERSON, 2004; VIEIRA et al., 2012). 
Tabela 1. Valores de critério de informação de Akaike corrigido (AICC) para as estruturas de variância e covariância modeladas

\begin{tabular}{lcccc}
\hline \multirow{2}{*}{ Variáveis } & \multicolumn{4}{c}{ Estruturas de Variância e Covariância } \\
\cline { 2 - 5 } & $\mathrm{VC}$ & $\mathrm{CS}$ & $\mathrm{AR}(1)$ & $\mathrm{UN}$ \\
\hline MS & $-15,5$ & $-16,7$ & $-14,4$ & $-10,5$ \\
PB & $-89,1$ & $-87,2$ & $-86,9$ & $-83,2$ \\
PIDA & -60 & $-57,8$ & $-58,4$ & $-50,1$ \\
PIDN & $-35,2$ & $-35,5$ & $-30,6$ & $-33,6$ \\
CT & $-78,6$ & $-76,9$ & $-76,4$ & $-67,7$ \\
CHO's & $-58,1$ & $-56,9$ & $-59,2$ & $-53,5$ \\
FDN & $-73,6$ & $-71,5$ & $-71,0$ & $-64,6$ \\
LIG & $-72,2$ & $-70,2$ & $-72,3$ & $-65,5$ \\
EE & $-96,8$ & $-94,8$ & $-94,5$ & $-85,8$ \\
MM & $-114,8$ & $-112,8$ & $-112,6$ & $-110,0$ \\
$V f_{1}$ & 110,9 & 109,0 & 114,4 & 118,9 \\
$k_{1}$ & $-219,4$ & $-223,3$ & $-217,6$ & $-221,4$ \\
$k_{2}$ & $-308,8$ & $-306,8$ & $-306,7$ & $-303,6$ \\
$V f_{2}$ & 123,7 & 125,4 & 125,8 & 129,2 \\
$\lambda$ & 34,3 & 35,2 & 36,4 & 41,1 \\
\hline MS = matéria seca; PB $=$ proteína bruta; PIDA $=$ proteína insolúvel em detergente ácido; PIDN $=$ \\
proténa insolúvel em detergente neutro; CHO's, = carboidratos solúveis; CT = carboidratos totais; \\
FDN = fibra em detergente neutro; LIG = lignina; EE = extrato etéreo; MM = matéria mineral; $V f_{1}=$ \\
volume máximo de gás produzido pela degradação da fração solúvel de rápida digestão; $k_{1}=$ taxa \\
espeçifica de produção de gás pela degradação da fração solúvel de rápida digestão; $k_{2}=$ taxa específica \\
de produção de gás pela degradação da fracção insolúvel potencialmente degradável de digestão lenta; \\
$V f_{2}=$ volume máximo de gás produzido pela degradação da fracção insolúvel potencialmente \\
degradável de digestão lenta; $\lambda=$ latência.
\end{tabular}

Em relação aos parâmetros estimados para a cinética de degradação, a matriz $\mathrm{VC}$ teve os menores valores de AICC para os parâmetros $k_{2}$ (taxa específica de produção de gases pela degradação da fração insolúvel potencialmente degradável de lenta digestão), $V f_{2}$ (volume máximo de gases produzidos pela degradação da fração insolúvel potencialmente degradável de lenta digestão) e $\lambda$ (fase de latência) enquanto para os parâmetros $V f_{1}$ (volume máximo de gases produzidos pela degradação da fração solúvel de rápida digestão) e $k_{l}$ (taxa específica de produção de gases pela degradação da fração solúvel de rápida digestão) os menores valores de AICC foram para a matriz CS (Tabela
1). No entanto, o valor de $\Delta_{\mathbf{r}}$ da matriz VC ficou entre 0 e 2 (Tabela 2) para o parâmetro $V f_{1}$ e foi escolhida por sua maior simplicidade. $\mathrm{O}$ mesmo procedimento não foi tomado para o parâmetro $k_{l}$, pois o valor de $\Delta_{\mathrm{r}}$ de todas as outras matrizes foi maior do que dois, permanecendo a escolha da matriz CS para o referido parâmetro (Tabela 2).

Realizou-se a análise de regressão para $\mathrm{PB}, \mathrm{CT}, \lambda$ e $k_{1}$ cujos valores de $\mathrm{p}$ foram inferiores ao nível de significância de 0,05 (Tabela 3).

Para os valores de $k_{1}$ refez-se a análise de regressão usando o procedimento robustreg do SAS, que penaliza os outliers de forma a reduzir seu efeito nos resultados. 
Tabela 2. Matriz escolhida pela diferença entre os valores de critério de informação de Akaike corrigido $\left(\Delta_{\mathrm{r}}\right)$ para cada parâmetro, probabilidade de verossimilhança $\left(\mathrm{W}_{\mathrm{r}}\right)$ e verossimilhança relativa $\left(\mathrm{ER}_{\mathrm{r}}\right)$

\begin{tabular}{lcccc}
\hline Parâmetro & Matriz & $\Delta_{\mathrm{r}}$ & $\mathrm{W}_{\mathrm{r}}$ & $\mathrm{ER}_{\mathrm{r}}$ \\
\hline MS & VC & 1,2 & 0,2873 & 1,82 \\
PB & VC & 0,0 & 0,5643 & 1,00 \\
PIDA & VC & 0,0 & 0,5589 & 1,00 \\
PIDN & VC & 0,0 & 0,3688 & 1,16 \\
CT & VC & 0,0 & 0,5667 & 1,00 \\
CHO's & VC & 1,1 & 0,2957 & 1,73 \\
FDN & VC & 0,0 & 0,6122 & 1,00 \\
LIG & VC & 0,1 & 0,4075 & 1,05 \\
EE & VC & 0,0 & 0,5922 & 1,00 \\
MM & VC & 0,0 & 0,5582 & 1,00 \\
$V f_{1}$ & VC & 1,9 & 0,2647 & 2,59 \\
$k_{1}$ & CS & 0,0 & 0,6302 & 1,00 \\
$k_{2}$ & VC & 0,0 & 0,5580 & 1,00 \\
$V f_{2}$ & VC & 0,0 & 0,5431 & 1,00 \\
$\lambda$ & VC & 0,0 & 0,4948 & 1,00 \\
\hline MS = matéria seca; PB $=$ proteína bruta; PIDA = proteína insolúvel em detergente ácido; PIDN = proteína \\
insolúvel em detergente neutro; CHO’s = carboidratos solúveis; CT = carboidratos totais; FDN = fibra em \\
detergente neutro; LIG = lignina; EE = extrato etéreo; MM, matéria mineral; $V f_{1}=$ volume máximo de gás \\
produzido pela degradação da fração solúvel de rápida digestão; $k_{1}=$ taxa específica de produção de gás \\
pela degradação da fração solúvel de rápida digestão; $k_{2}=$ taxa específica de produção de gás pela \\
degradação da fração insolúvel potencialmente degradável de digestão lenta; $V f_{2}=$ volume máximo de gás \\
produzido pela degradação da fracção insolúvel potencialmente degradável de digestão lenta; $\lambda=$ latência.
\end{tabular}

Tabela 3. Média e intervalo de confiança (IC 95\%) dos parâmetros em relação aos tratamentos

\begin{tabular}{lcccc}
\hline \multirow{2}{*}{ Variáveis } & \multicolumn{4}{c}{ Média $\left(\mathrm{g} \mathrm{kg}^{-1}\right) /$ níveis de tratamento } \\
\cline { 2 - 5 } & 0 & 180 & 360 & 720 \\
\hline MS & $147 \pm 16$ & $166 \pm 37$ & $136 \pm 39$ & $160 \pm 79$ \\
PB & $220 \pm 13$ & $246 \pm 21$ & $255 \pm 21$ & $262 \pm 19$ \\
PIDA & $26 \pm 10$ & $34 \pm 10$ & $41 \pm 15$ & $42 \pm 14$ \\
PIDN & $136 \pm 30$ & $143 \pm 37$ & $136 \pm 27$ & $133 \pm 45$ \\
CT & $660 \pm 17$ & $636 \pm 26$ & $621 \pm 27$ & $615 \pm 26$ \\
CHO's & $105 \pm 25$ & $92 \pm 17$ & $83 \pm 20$ & $92 \pm 20$ \\
FDN & $464 \pm 32$ & $459 \pm 16$ & $475 \pm 23$ & $451 \pm 35$ \\
LIG & $51 \pm 11$ & $56 \pm 15$ & $63 \pm 12$ & $59 \pm 14$ \\
EE & $29 \pm 4$ & $29 \pm 7$ & $31 \pm 6$ & $25 \pm 7$ \\
MM & $90 \pm 5$ & $90 \pm 8$ & $93 \pm 6$ & $97 \pm 12$ \\
$V f 1$ & $13,02 \pm 1,33$ & $13,54 \pm 0,75$ & $13,07 \pm 1,00$ & $12,79 \pm 0,76$ \\
$k 1$ & $0,09 \pm 3,8010^{-3}$ & $0,09 \pm 5,0910^{-3}$ & $0,09 \pm 3,3310^{-3}$ & $0,09 \pm 8,8010^{-3}$ \\
$k 2$ & $0,03 \pm 1,2910^{-3}$ & $0,02 \pm 1,7810^{-3}$ & $0,02 \pm 1,0110^{-3}$ & $0,02 \pm 1,4210^{-3}$ \\
$V f 2$ & $13,86 \pm 1,27$ & $12,22 \pm 1,24$ & $12,27 \pm 0,88$ & $12,67 \pm 1,39$ \\
$\lambda$ & $0,56 \pm 0,24$ & $0,80 \pm 0,28$ & $1,06 \pm 0,34$ & $0,81 \pm 0,33$ \\
\hline MS & & & 0,28
\end{tabular}

$\mathrm{MS}=$ matéria seca; $\mathrm{PB}=$ proteína bruta; $\mathrm{PIDA}=$ proteína insolúvel em detergente ácido; $\mathrm{PIDN}=$ proteína insolúvel em detergente neutro; $\mathrm{CHO}$ 's= carboidratos solúveis; $\mathrm{CT}=$ carboidratos totais; $\mathrm{FDN}=$ fibra em detergente neutro; $\mathrm{LIG}=$ lignina; $\mathrm{EE}=$ extrato etéreo; $\mathrm{MM}=$ matéria mineral; $V f_{1=}$ volume máximo de gás produzido pela degradação da fração solúvel de rápida digestão; $k_{1=}$ taxa específica de produção de gás pela degradação da fração solúvel de rápida digestão; $k_{2}$ taxa específica de produção de gás pela degradação da fracção insolúvel potencialmente degradável de digestão lenta; $V f_{2=}$ volume máximo de gás produzido pela degradação da fracção insolúvel potencialmente degradável de digestão lenta; $\lambda=$ latência. 
A análise de regressão robusta resultou em efeito não significativo para o nível de adubação sobre 0 parâmetro $k_{1}$ (Tabela 4). O parâmetro $\lambda$ variou de forma quadrática em função do nível de adubação (Tabela 4 ).

A grande maioria das variáveis estudadas não apresentou correlação significativa entre os dados obtidos na mesma parcela ao longo do tempo. Por isso, a matriz VC pôde ser considerada a melhor opção para modelar a estrutura de variância e covariância das variáveis, com a exceção do parâmetro $k_{1}$ cuja melhor matriz foi a CS. A estrutura da matriz CS prediz a existência de uma correlação uniforme entre os dados obtidos na mesma unidade experimental em diferentes tempos (LITTELL et al., 2006).

Tabela 4. Equações de regressão e respectivos valores de $\mathrm{P}$ para as variáveis bromatológicas e parâmetros da cinética de degradação

\begin{tabular}{|c|c|c|}
\hline Variáveis & Equações de regressão & $\mathrm{p}$ - valor \\
\hline MS & $\mathrm{y}=\overline{\mathrm{y}}$ & 0,7208 \\
\hline PB & $y=228,88+0,0535 x$ & 0,0006 \\
\hline PIDA & $\mathrm{y}=\overline{\mathrm{y}}$ & 0,1106 \\
\hline PIDN & $y=\bar{y}$ & 0,9450 \\
\hline CT & $y=651,60-0,0588 x$ & 0,0027 \\
\hline CHO's & $\mathrm{y}=\overline{\mathrm{y}}$ & 0,3244 \\
\hline FDN & $y=\bar{y}$ & 0,4710 \\
\hline LIG & $y=\bar{y}$ & 0,4358 \\
\hline $\mathrm{EE}$ & $y=\bar{y}$ & 0,3638 \\
\hline MM & $\mathrm{y}=\overline{\mathrm{y}}$ & 0,4221 \\
\hline$V f_{l}$ & $\mathrm{y}=\overline{\mathrm{y}}$ & 0,5764 \\
\hline$k_{1}$ & $\mathrm{y}=\overline{\mathrm{y}}$ & $0,1467 *$ \\
\hline$k_{2}$ & $y=\bar{y}$ & 0,2436 \\
\hline$V f_{2}$ & $\mathrm{y}=\overline{\mathrm{y}}$ & 0,0652 \\
\hline$\lambda$ & $y=0,53+2,210^{-3} x-2,5710^{-6} x^{2}$ & 0,0151 \\
\hline \multicolumn{3}{|c|}{$\begin{array}{l}\text { MS = matéria seca; } \mathrm{PB}=\text { proteína bruta; PIDA = proteína insolúvel em detergente ácido; PIDN = proteína } \\
\text { insolúvel em detergente neutro; } \mathrm{CHO} \text { 's = carboidratos solúveis; } \mathrm{CT}=\text { carboidratos totais; } \mathrm{FDN}=\text { fibra em } \\
\text { detergente neutro; } \mathrm{LIG}=\text { lignina; } \mathrm{EE}=\text { extrato etéreo; } \mathrm{MM}=\text { matéria mineral; } V f_{l}=\text { volume máximo de } \\
\text { gás produzido pela degradação da fração solúvel de rápida digestão; } k_{l} \text { = taxa específica de produção de } \\
\text { gás pela degradação da fração solúvel de rápida digestão; } k_{2}=\text { taxa específica de produção de gás pela } \\
\text { degradação da fracção insolúvel potencialmente degradável de digestão lenta; } V f_{2}=\text { volume máximo de gás } \\
\text { produzido pela degradação da fracção insolúvel potencialmente degradável de digestão lenta; } \lambda=\text { latência. }\end{array}$} \\
\hline
\end{tabular}

A resteva da cultura do ano anterior pode ter deixado um resíduo de nitrogênio no solo o que pode ter interferido na resposta da planta, pois em apenas 30 dias, mais da metade da matéria seca das leguminosas já se encontra decomposta (RANELLS \& WAGGER, 1992; RANELLS \& WAGGER, 1996; AITA \& GIACOMINI, 2003; CANTARELLA, 2007). Essa condição aproxima o experimento às praticas adotadas na integração lavourapecuária.
Os teores de MS não apresentaram diferenças significativas entre os tratamentos. Grecco et al. (2011), obteve em torno de $240 \mathrm{~g} \mathrm{~kg}^{-1}$ para o teor de MS, valor superior ao observado em todos os tratamentos; enquanto Neres et al. (2012) e Rodrigues \& Godoy (2000), nos meses de Junho e Julho, observaram resultados similares ao deste experimento. Luz (2013) observou, trabalhando com a IPR 61, também na região de Dois Vizinhos, o valor de $126 \mathrm{~g} \mathrm{~kg}^{-1}$ no teor de MS; e Pereira et al. (1993), com aveia branca, 
encontrou valores de $84 \mathrm{~g} \mathrm{~kg}^{-1}$ de MS, ou seja, abaixo dos observados no presente estudo.

$\mathrm{O}$ teor de $\mathrm{PB}$ da aveia aumentou linearmente até a dose de $720 \mathrm{~kg} \mathrm{ha}^{-1} \mathrm{de}$ $\mathrm{N}$, não chegando à fase assintótica de reposta da concentração de $\mathrm{PB}$ da aveia branca em função da dose de N. Pin (2009), Grecco et al. (2011) e Soares et al. (2013), trabalhando com a IPR 126, e López \& Mühlbach (1991), Pereira et al (1993), Cecato et al. (1998) e Luczyszyn \& Rossi Junior (2007), trabalhando com outras variedades de forrageiras temperadas, encontraram valores de PB abaixo dos observados neste experimento até mesmo no nível 0 de $\mathrm{N}$, mas apenas Grecco et al. (2011) não realizou aplicação de $\mathrm{N}$ em cobertura, após os cortes.

Os teores de PB da aveia, mesmo sem adubação (Tabela 3), estão bem acima do valor crítico de $80 \mathrm{~g}$ de $\mathrm{PB}$ por $\mathrm{kg}$ de MS necessário para manter um crescimento microbiano adequado e consequentemente permitir uma eficiente degradação da fibra do rúmen (VAN SOEST, 1994).

Não foi observado influência dos níveis de $\mathrm{N}$ sobre o PIDA, similar às informações obtidas por Moreira et al. (2001) pesquisando a aveia preta IAPAR 61.

$\mathrm{O}$ equilíbrio entre carboidratos e compostos nitrogenados é de fundamental importância para a saúde e o desempenho do animal, pois a composição química e a degradação dos alimentos no rúmen determinam o crescimento microbiano e a produção de ácidos graxos voláteis, sendo estas, respectivamente, as principais fontes de proteína e energia para os bovinos (CULLEN et al., 1986; RUSSELL et al., 1992; SNIFFEN et al., 1992; VAN SOEST, 1994; EKINCI \& BRODERICK, 1997).

$\mathrm{O}$ teor de CT da aveia diminuiu linearmente em função das doses de $\mathrm{N}$, enquanto a concentração de $\mathrm{PB}$ aumentou. Segundo Sinclair et al. (1991), a relação ideal entre nitrogênio e carboidrato total $(\mathrm{N}: \mathrm{CT})$ para otimizar a degradação microbiana é de $32 \mathrm{~g}$ de $\mathrm{N}$ $\mathrm{kg}^{-1}$ de CT, essa relação para o nível 0 de adubação nitrogenada foi de $53 \mathrm{~g} \mathrm{~N} \mathrm{~kg}^{-1}$

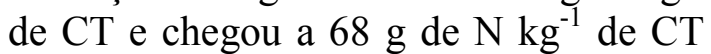
no nível 720, ou seja, mesmo sem adubação nitrogenada, a relação N:CT da aveia já estava desfavorável para a degradação ruminal devido a excesso de $\mathrm{N}$ e essa relação piorou ainda mais ao se aumentar o nível de adubação nitrogenada (Tabela 4). Segundo Corsi (1994) a adubação nitrogenada acaba por reduzir o teor de CHO's das forrageiras, mas diferentemente dos CT, o teor de CHO's não sofreu influência da adubação nitrogenada no presente trabalho, representando $14,5 \%$ dos CT.

Não foi observada alteração nos teores de FDN da IPR 126 em função da adubação nitrogenada (Tabela 2), assim como Moreira et al. (2001) ao estudar níveis de $\mathrm{N}$ aplicados a outros cultivares de aveia. Grecco et al. (2011) e Moreira et al (2001) observaram valores similares aos deste estudo, enquanto Pin (2009) e Soares et al. (2013) encontraram valores médios de FDN acima de $570 \mathrm{~g} \mathrm{~kg}^{-}$ ${ }^{1}$.Assim como os teores de EE e MM, o teor de lignina da IPR 126 não se alterou com o nível de adubação (Tabela 3 ) e foi bastante próximo do encontrado por Janusckiewicz et al. (2010).

Não se observou efeitos significativos das doses de $\mathrm{N}$ na maioria dos parâmetros de cinética de degradação, com exceção do parâmetro $\lambda$ que teve comportamento quadrático em função do aumento da adubação (Tabela 4). A latência $(\lambda)$ depende da hidratação das partículas, da anatomia da planta e da massa microbiana no rúmen (JUNG \& ALLEN, 1995) e pode, portanto, ser influenciada pela idade e espécie da forrageira.

A fase assintótica da concentração de proteína bruta em função da adubação não foi atingida mesmo utilizando altas 
doses de nitrogênio. No entanto, deve-se levar em consideração a máxima eficiência técnica ao realizar adubações nitrogenadas em altas doses, além de verificar a viabilidade econômica desta prática. Dentre os parâmetros da cinética de produção de gases, apenas a latência teve influência da adubação.

Fritzsons (1999) mostra em seu trabalho os riscos de contaminação ambiental, principalmente do solo e água, através da lixiviação, ao se utilizar fontes de nitrogênio na produção animal e vegetal, levando a riscos para a saúde pública, sendo ainda um dos principais gases responsáveis pelo efeito estufa.

Deve-se considerar que o período experimental foi de baixa precipitação com temperaturas elevadas, condições atípicas para os períodos de inverno e primavera, podendo ter interferido na absorção de nitrogênio pelas plantas, pois a fonte de suplementação utilizada foi a uréia, e a mesma necessita de condições de umidade e temperatura para ser melhor aproveitadas pelas plantas (FRIZZONE, 1995; TEIXEIRA FILHO, 2010).

Neste experimento a aveia IPR 126 demonstrou resposta a altas doses de nitrogênio, verificado pelo aumento linear no teor de proteína bruta, no entanto, ao se analisar os potenciais riscos de contaminação ambiental e viabilidade econômica, não recomendamos utilizar doses elevadas de nitrogênio, visto ainda que esta prática leva a um desequilíbrio na relação entre nitrogênio e carboidratos totais, comprovados com os resultados obtidos neste experimento, os quais revelaram que mesmo sem a adição de nitrogênio a IPR 126 já apresentava níveis de acima dos desejados para um bom crescimento bacteriano.

\section{REFERÊNCIAS}

ABREU, M.L.C; VIEIRA, R.A.M.; ROCHA, N.S.; ARAUJO, R.P.; GLÓRIA, L.S.; FERNANDES, A.M.; LACERDA, P.D. de; GESUALDI JUNIOR, A. Clitoriaternatea L. as a potential high quality forage legume. Journal of Animal Science, v.27, n.2, p.169-178, 2014.

ADAMI, P.F.; PITTA, C.S.R. (Eds.). Pastagem e bovinocultura de leite. Goioerê: Instituto Federal do Paraná, 2012.

AITA, C.; GIACOMINI, S.J.

Decomposição e liberação de nitrogênio de resíduos culturais de plantas de cobertura de solo solteiras e consorciadas. Revista Brasileira

Ciência do Solo, v.27, p.601-612, 2003.

AL-KARAKI, G.; AL-AJMI, A.; OTHMAN, Y. Response of soiless grown bell pepper cultivars to salinity. Acta Horticulturae, v.807, n.2, p.227232, 2009.

ALVARES, C.A.; STAPE, J.L.; SENTELHAS, P.C.; GONÇALVES, J.L.M.; SPAROVEK, G. Köppen's climates classification map for brazil. Meteorologische Zeitschrift, v.22, n.6, p.711-728, 2013..

BURNHAM, K.P.; ANDERSON, D.R. Multimodel Inference: Understanding AIC and BIC in Model Selection.

Sociological Methods Research, v.33, p.261-304, 2004.

BURTON, G.W.; MONSON, W.G.

Registration of "Tifton 78"

bermudagrass. Crop Science, v.28, n.2, p.187-188, 1988. 
CANTARELLA, H. Nitrogênio. In: NOVAIS, R.F.; ALVAREZ V., V.H.; BARROS, N.F.; FONTES, R.L.F.; CANTARUTTI, R.B.; NEVES, J.C.L. (Eds.). Fertilidade do solo. Viçosa, MG, Sociedade Brasileira de Ciência do Solo, 2007. p.375-470. .

CARVALHO, P.C.F.; ROCHA, L.M.; BAGGIO, C.; MACARI, S.; KUNRATH, T.R.; MORAES, A. Forrageiras de Clima Temperado. In: FONSECA, D.M.; MARTUSCELLO, J.A. (Ed.). Plantas Forrageiras. Viçosa, MG: Universidade Federal de Viçosa, 2010. p.494-537.

CECATO, U.; SARTI, L.L.;

SAKAGUTI, E.S.; DAMASCENO, J.C.; REZENDE, R.; SANTOS, G.T.

Avaliação de cultivares e linhagens de aveia (Avena spp.). Acta Scientiarum, v.20, n.3, p.347-354, 1998.

CORSI, M. Adubação nitrogenada das pastagens. In: PEIXOTO, A.M.; MOURA, J.C.; FARIA, V.P. (Eds). Pastagens: fundamentos da exploração racional. Piracicaba, SP : FEALQ, 1994. p.155-164. (Atualização em Zootecnia, 10).

CULLEN, A.J.; HARMON, D.L.; NAGARAJA, T.G. In Vitro Fermentation of Sugars, Grains, and By-Product Feeds in Relation to Initiation of Ruminal Lactate Production. Journal of Dairy Science, v.69, p.2616-2621, 1986.

CUSTÓDIO, T.N.; BARBIN, D. Comparação de modelos mistos visando à estimação do coeficiente de herdabilidade para dados de proporções. Revista de Matemática e Estatística, v.23, n.2, p.23-31, 2005.

EKINCI, C.; BRODERICK, G.A. Effect of Processing High Moisture Ear Corn on Ruminal Fermentation and Milk Yield. Journal of Dairy Science, v.80, p.32983307, 1997.

\section{EMBRAPA. Sistema Brasileiro de} Classificação de Solos. 2.ed. Brasilia, DF, 2006. 412p.

FRIZZONE, J.A.; TEODORO, R.E.F.; PEREIRA, A.S.; BOTREL, T.A. lâminas de agua e doses de nitrogênio na produção de aveia (Avena sativa L.) para forragem. Scientia Agricola, v.52, n.3, p.578-586, 1995.

FRITZSONS, E. Avaliação do impacto da contaminação por nitrogênio na bacia hidrográfica cárstica de fervida / Ribeirão das Onças - Colombo / PR. 1999. 186f. Dissertação (Mestrado em Ciências Florestais) - Curso de Pós Graduação em Engenharia Florestal, Universidade Federal do Paraná, Curitiba.

GOERING, H.K.; VAN SOEST, P.J. Forage fiber analyses (Apparatus, regents, procedures, and some applications). Washington: United States Department of Agriculture, 1975. 20p. (Agriculture Handbook, 379).

GOMES, J.F.; REIS, J.C.L. Produção de Forrageiras Anuais de Estação Fria no Litoral do Rio Grade do Sul. Revista Brasileira de Zootecnia, v.28, n.4, p. 668-674, 1999.

GRECCO, F.C.A.R.; CUNHA FILHO, L.F.C.; OKANO, W.; SILVA, L.C. da; ZUNDT, M.; VIANNA, L.C.

Produtividade e composição química de gramíneas temperadas na cidade de Arapongas-PR. Colloquium Agrariae, v.7, n.1, p.17-23, 2011.

\section{INSTITUTO AGRONÔMICO DO} PARANÁ - IAPAR. Os múltiplos usos da Aveia branca IAPAR 126. 2007. Disponível em: $<$ http://www.iapar.br/modules/noticias/ar ticle.php? storyid $=16>$. Acesso em: 22 jul. 2013. 
JANUSCKIEWICZ, E.R.; PRADO, F.; RUGGIERI, A.C.; RAPOSO, E.; CHIARELLI, C.B.; ROSSINI, D.; FONTANELI, R.S. Massa e composição química de três forrageiras de inverno manejadas sob duas alturas de resíduo e pastejo rotacionado. ARS Veterinaria, v.26, n.1, p.047-052, 2010.

JUNG, H.G.; ALLEN, M.S.

Characteristics of plant cell walls affecting intake and digestibility of forages by ruminants. Journal of Animal Science, v.73, p.2774-2790, 1995.

LIMA, E.V.; ARAGÃO, C.A.; MORAIS, O.M.; TANAKA, R.; FILHO, H.G. Adubação NK no desenvolvimento e na concentração de macronutrientes no florescimento do feijoeiro. Scientia Agricola, v.58, n.1, p.125-129, 2001.

LITTEL, R.C.; MILLIKEN, G.; STROUP, W.W.; WOLFINGER, R.D.;

SHABENBERGER, O. SAS System for Mixed Models. Cary, NC: SAS Institute Inc., 1996.

LITTEL, R.C.; HENRY, P.R.; AMMERMAN, C.B. Statistical analysis of repeated measures data using SAS procedures. Journal of Animal Science, v.76, n.4, p.1216-1231, 1998.

LITTEL, R.C.; MILLIKEN, G.A.; STROUP, W.W.; WOLFINGER, R.D.; SCHABENBERGER, O. SAS ${ }^{\circledR}$ for Mixed Models. $2^{\text {nd }}$ ed. Cary, NC: SAS Institute Inc., 2006.

LÓPEZ, S.E.; MÜHLBACH, P.R.F. Efeito de diferentes tratamentos na composição químico-bromatológica da aveia branca (Avena sativa L.) conservada nas formas de silagem ou feno. Ver. Sociedade

Brasileira de Zootecnia, v.20, n.4, p.333338, 1991.
LUCZYSZYN, V.C.; ROSSI JUNIOR, P. Composição bromatológica de pastagens de inverno submetidas a pastejo por ovinos, obtidas por fístulas esofágicas. Revista Acadêmica, v.5, n.4, p.345-351, 2007.

\section{LUZ, P.A.S. Consumo e digestibilidade} de aveia preta em caprinos de corte recebendo quatro níveis de suplemento. 2013. 64f. Dissertação (Mestrado em Zootecnia) - Programa de Pós Graduação em Zootecnia. Universidade Tecnológica Federal do Paraná, Dois Vizinhos.

MAACK, R. Geografia Física do Estado do Paraná. Curitiba: Max Roesner, 1968. 350p.

MANNETJE, L.T. Measuring biomass of grassland vegetation. In: MANNETJE, L.T.; JONES, R.M. (Eds.). Field and laboratory methods for grassland and animal production research. Cambridge: CABI, 2000. p.151-178.

MERTENS, D.R. Gravimetric determination of amylase-treated neutral detergent fiber in feeds with refluxing in beakers or crucibles: collaborative study. Journal of AOAC International, v.85, n. 6, p. 1217-1240, 2002.

MOREIRA, F.M.S.; SIQUEIRA, J.O. Microbiologia e Bioquímica do Solo. 2.ed. Lavras: UFLA, 2006.

MOREIRA, A.L.; RUGGIERI, A.C.; REIS, R.A.; SEIXAS, P.F.; PEDREIRA, M.S.; GODOY, R. Avaliação da aveia Preta e de genótipos de aveia Amarela para produção de forragem. ARS Veterinária, v.21, p.175-182, 2005. Supl.

MOREIRA, F.B.; CECATO, U.; PRADO, I.N.; WADA, F.Y.; REGO, F.C.A.; NASCIMENTO, W.G. Avaliação de aveia preta cv 'Iapar 61' submetida a níveis crescentes de nitrogênio em área proveniente de cultura de soja. Acta Scientiarum, v.23, n.4, p.815-821, 2001. 
NERES, M.A.; CASTAGNARA, D.D.; OLIVEIRA, P.S.R.; OLIVEIRA, E.; JOBIM, C.C.; TRES, T.T.; MESQUITA, E.E. IPR 126 white oat forage potential under free growth, cutting and grazing at two management Heights. Revista Brasileira de Zootecnia, v.41, n.4, p.889-897, 2012.

NIMER, E. Clima. In: IBGE. Diretoria Técnica. Geografia do Brasil. Rio de Janeiro: SERGRAF, 1977. v.5, p.35-79.

OLSON, R.A.; KURTZ, L.T. Crop nitrogen requirements, utilization and fertilization. in STEVENSON, F.J. (Ed.). Nitrogen in agricultural soils. Madison. Wisconsin: ASA/CSSA/SSSA, 1982. p.567-604. (Agronomy, 22).

PEREIRA, O.G.; OBEID, J.A.; GOMIDE, J.A.; QUEIROZ, A.C.; VALADARES FILHO, S.C.

Produtividade e valor nutritive de aveia (Avena sativa), milheto

(PennisetumamericanumL.), e de um hibrido de Sorghum bicolor $x S$. sudanense. Sociedade Brasileira de Zootecnia, v.22, n.1, p.22-30, 1993.

PIN, E.A. Rendimento de forrageiras anuais de inverno em diferentes épocas de semeadura. 2009. 135f. Dissertação (Mestrado em Agronomia) Universidade Tecnológica Federal do Paraná, Pato Branco.

RANELLS, N.N.; WAGGER, M.G. Nitrogen release from crimson clover in relation to plant growth stage and composition. Agronomy Journal, v.84, p.424-430, 1992.

RANELLS, N.N.; WAGGER, M.G. Nitrogen release grass and legume cover crop monocultures and biocultures. AgronomyJournal, v.88, p.777-782, 1996.
RODRIGUES, A.A.; GODOY, R. Efeito do pastejo restringido em aveia sobre a produção de leite. Pesquisa Agropecuária Brasileira, v.35, n.3, p.551-556, 2000.

ROSO, C.; RESTLE, J.; SOARES, A.B.; ALVES FILHO, D.C.; BRONDANI, I.L. Produção e qualidade de forragem da mistura de gramíneas anuais de estação fria sob pastejo contínuo. Revista Brasileira de Zootecnia, v.28, n.3, p.459-467, 1999.

RUSSELL, J.B.; O'CONNOR, J.D.; FOX, D.G.; VAN SOEST, P.J.; SNIFFEN, C.J.A netcarbohydrate and protein system for evaluating cattle diets: I - Ruminal fermentation. Journal of Animal Science, v.70, p.3551-61, 1992.

SANTI, A.; AMADO, T.J.C.; ACOSTA, J.A.A. Adubação nitrogenada na aveia preta. I - Influência na produção de matéria seca e ciclagem de nutrientes sob sistema plantio direto. Revista Brasileira Ciência do Solo, v.27, n.6, 2000.

STATISTICAL ANALYSIS SYSTEM SAS. System for Microsoft Windows: release 8.2. Cary, 2001.

SCHOFIELD, P.; PITT, R.E.; PELL, A.N. Kinetics of fiber digestion from in vitro gás production. Journal of Dairy Science, v.72, n.11, p.2980-2991, 1994.

SCHOSSLER, T.R.; MACHADO, D.M.; ZUFFO, A.M.; ANDRADE, F.R.;

PIAUILINO, A.C. Salinidade: efeitos na fisiologia e na nutrição mineral de plantas. Enciclopédia Biosfera, Centro Científico Conhecer, v.8, n.15, p.1563-1578, 2012.

SILVA, D.J.; QUEIROZ, A.C. Análise de alimentos: métodos químicos e biológicos. 3.ed. Viçosa, MG: Universidade Federal de Viçosa, 2002. 
SINCLAIR, L.A.; GALBRAITH, H.;

SCAIFE, J.R. Effect of dietary protein concentration and cimaterol on growth and body composition of entire male lambs. Animal Feed Science and Technology, v.34, p.181-192, 1991.

SNIFFEN, C.J.; O'CONNOR, J.D.; VAN SOEST, P.J.;FOX, D.G.; RUSSELL, J.B. A net carbohydrate and protein system for evaluating cattle diets: carbohydrate and protein availability. Journal of Animal Science, v.70, n.12, p.35623577, 1992.

SOARES, A.B.; PIN, E.A.; POSSENTI, J.C.; Valor nutritivo de plantas forrageiras de inverno em quatro épocas de semeadura. Ciência Rural, v.43, n.1, p.120-125, 2013.

SOUZA, F.H.; PEREIRA, V.A.S.; CASTAGNARA, D.D.; MESQUITA, E.E.; BAMBERG, R.; RADIS, A.C.; SOUZA, L.C. Altura do dossel forrageiro e relação folha/colmo das aveias IAPAR 61 e IPR 126 em três épocas de semeadura na região oeste do Paraná. Zootec, Associação Brasileira de zootecnistas. Águas de Lindóia, SP: USP, 2009.

TEIXEIRA FILHO, M.C.M..; BUZETTI, S.; ANDREOTTI, M.; ARF, O.;

BENETT, C.G.S. Doses, fontes e épocas de aplicação de nitrogênio em trigo irrigado em plantio direto. Pesquisa Agropecuária Brasileira, v.45, n.8, p.797-804, 2010.

VAN SOEST, P.J. Nutritional ecology of the ruminant. 2.ed. Ithaca: Cornel University Press, 1994.

VAN SOEST, P.J.; ROBERTSON, J.B. Analysis of forages and fibrous foods. A laboratory Manual for Animal Science 613. Ithaca, NY: Cornell University, 1985. 202p.
VIEIRA, R.A.M.; CAMPOS, P.R.S.S.; DA SILVA, J.F.C.; TEDESCHI, L.O.; TAMY, W.P. Heterogeneity of the digestible insoluble fiber of selected forages in situ. Animal Feed Science and Technology, v.171, p.154-166, 2012.

WILM, H.G.; COSTELLO, D.F.; KLIPPLE, G.E. Estimating forage yield by the double sampling methods.

Journal of American Society of Agronomy, v.36, p.194-203, 1944.

Data de recebimento: 06/10/2015

Data de aprovação: 28/11/2016 